\title{
Measuring the Effects on Quality of Life and Alcohol Consumption of a Program to Reduce Binge Drinking in Spanish Adolescents
}

Ana Magdalena Vargas-Martínez ${ }^{a, b}$, Marta Trapero-Bertran ${ }^{b}$, Marta Lima-Serrano $^{a}$, Nana Anokye $^{c}$, Subhash Pokhrel ${ }^{c}$, Toni Mora ${ }^{b}$.

Affiliations

aDepartment of Nursing, Faculty of Nursing, Physiotherapy and Podiatry, University of Seville, Seville, Spain

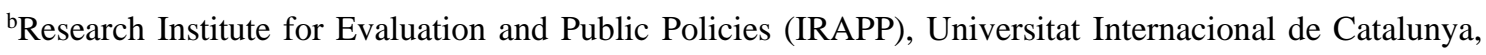
Barcelona, Spain

'Health Economics Research Group (HERG), Brunel University, Uxbridge, London, UK.

\section{Correspondence author:}

Marta Lima-Serrano. Department of Nursing. Faculty of Nursing, Physiotherapy and Podiatry. University of Seville. c/Avenzoar 6, 41009, Seville, Spain. Mobile phone: +34 651330 654.Email: $\underline{\text { mlima@us.es }}$

Email addresses: (A.M. Vargas) avargas5@us.es, (M. Trapero) mtrapero@uic.es, (N. Anokye) Nana.Anokye@brunel.ac.uk, (S. Pokhrel) Subhash.Pokhrel@brunel.ac.uk, (T. Mora) tmora@uic.es

\section{Trial registration:}

Trial registration number (ClinicalTrials.gov): NCT03288896. This study was retrospectively registered on 19/09/2017.

\section{Funding}

This study has been prepared within the framework of the research project “ALCOHOL ALERT: Design, validation and evaluation of the program of selective prevention of alcohol abuse in adolescents: web-based computer-tailored intervention” 
(PI-0031-2014), financed by the Andalusian Public Foundation "Progress and Health" for the financing of research + innovation in biomedicine and in health sciences in Andalusia for the year 2014 (Health Counseling). This study has been partially funded by the Spanish Ministry of Economy and Competitiveness (MINECO) under the program "PROYECTOS I+D+I RETOS”, project: “Estilos de vida no saludables: herramientas para el análisis de politicas de salud”, Grant ECO2017-83771-C3-3-R. The funders had no influence on the conduct of this study or the drafting of this manuscript.

\section{Highlights}

- ALERTA ALCOHOL program was effective to reduce the binge drinking (BD).

- A higher adherence to program increases health-related quality of life (HRQoL).

- Age, family alcohol consumption and having partner negatively affected the HRQoL.

- Girls reported lower score in 'pain/discomfort' and 'anxiety/depression' of EQ5D-5L.

\section{Author Disclosures Section:}

\section{Role of Funding Source}

Nothing declared.

\section{Contributors}

Conceptualization of the study: AMVM, MLS, MTB; Analyses: AMVM, TM; Interpretation of results: AMVM, TM, MTB; Drafting the first version of the manuscript: AMVM, MTB; Revisions and approval of the manuscript: AMVM, MTB, MLS, TM, NA, SP.

\section{Conflict of Interest}


There are no conflicts of interest for any author of this paper. 


\section{Abstract}

Aim: To present a comparison between the effects on health due to a reduction in binge drinking (BD) and health-related quality of life (HRQoL), as a result of ALERTA ALCOHOL, an intervention aimed at reducing BD in Spanish adolescents.

Methods: A two-arm cluster randomized controlled trial was conducted with an intervention and a control group, randomized at the school level, following individuals over four months. The study population consisted of Andalusian adolescents aged 15 to 19 years who were enrolled in urban public high schools $(n=1247)$. Participants were assigned randomly to receive the intervention. The main outcome studied was the number of occasions of $\mathrm{BD}$ in the last 30 days, which was directly obtained from the answers given by the adolescents, and HRQoL measured with the EQ-5D-5L questionnaire. The model of estimation was the generalized estimating equations (GEE) approach.

Results: The program showed a BD reduction at the 4-month follow-up, although it was not shown to significantly increase the HRQoL in adolescents who reduced the number of occasions of $\mathrm{BD}$ and had received the intervention. However, it was shown that those who would predictably reduce the number of occasions of $\mathrm{BD}$ controlled by several sociodemographic variables perceived a higher HRQoL, as did those who had a greater adherence to the program.

Conclusions: Higher adherence to a web-based computer-tailored intervention to prevent $\mathrm{BD}$ in adolescents has a positive effect on decreasing the number of occasions of BD in adolescents as well as on increasing participants' HRQoL, although this second effect is very small, which could be due to the short follow-up time. This fact is quite important and should be assessed extensively to corroborate the results and to be translated into health policy. 
Keywords: adolescents, health-related quality of life, EQ-5D-5L, binge drinking, alcohol, intervention, prevention 


\section{Introduction}

According to the World Health Organization, in 2012, approximately 3.3 million deaths globally, 139 million DALYs (disability-adjusted life years), and 5\% of the global burden of disease and injury were attributable to alcohol consumption (World Health Organization, 2014). Moreover, it is known that children, adolescents and elderly people are typically more vulnerable to the negative effects of excessive alcohol consumption than other age groups (Hilton, 1987; Mäkelä and Mustonen, 2000; Midanik and Clark, 1995). Among young people, this vulnerability is related to binge drinking (BD), when a great amount of alcohol is consumed during short periods of time, mainly on weekends (Anderson, 2007; Calafat, 2007; Cortés et al., 2007; US Surgeon General, 2007).

BD has become a concern for health policy makers. At the international level, in 2015, the European School Survey Project on Alcohol and Other Drugs (ESPAD) study investigated the drinking habits of 96,046 adolescents born in 1999 and found that every third student (35\%) reported heavy episodic drinking in the past month. The term "heavy episodic drinking” is defined as drinking a minimum of five alcoholic beverages on one occasion at least once in the last 30 days and is therefore similar to BD. This study found high rates of alcohol use, particularly heavy alcohol use, although temporal trends over the past twenty years (between 1995 and 2015) indicated a positive development, with an overall decrease. However, changes in heavy episodic drinking were less pronounced, with overall rates declining from $36 \%$ to $35 \%$ over the past two decades. This drinking pattern was more frequent in Austria, Cyprus and Denmark, where almost half of the students reported heavy episodic drinking (ESPAD Group, 2016). In Spain, BD among young people is one of the main public health problems, as recognized in the Spanish National Plan on Drugs (2018). Although the 2016-2017 edition of the Survey on the Use 
of Drugs in Secondary Education (ESTUDES) found a 0.05\% reduction from 2014, the prevalence remains high, with $31.7 \%$ adolescents engaged in BD. Furthermore, it constitutes a serious socio-sanitary problem, with negative consequences such as disruptions in neural oscillations similar to those observed in persons with alcohol dependence (López-Caneda et al., 2014), a significantly less healthy diet (Mohamed and Ajmal, 2015) and a high probability of developing an alcohol use disorder in adulthood (Caamaño-Isorna et al., 2017; Grant et al., 2001; Spoelder et al., 2015), all of which result in a poor quality of life (QoL) (Luquiens et al., 2016). Therefore, it seems necessary to prevent or reduce this pattern of consumption to minimize the effects on health and quality of life.

In relation to the reduction or avoidance of $\mathrm{BD}$, a recent study carried out by Lammers et al. (2017) in The Netherlands, in 100 schools, applied a program called "Preventure", which was particularly effective in preventing the incidence of BD in students with a sensation-seeking personality, and preventing alcohol use among students with an anxiety sensitivity personality, four and six months after an intervention. They conclude that selective or tailored prevention seems to be more effective in changing alcohol misuse behaviour, more specifically, among high-risk young adolescents. Moreover, they added that no significant effects were revealed on personality traits due to problem drinking.. This may imply that curbing the growth of drinking in early onset drinkers may delay the onset of problem drinking over the longer term (beyond 12 months post-intervention).

The QoL measure captures the physical and mental well-being of an individual; his/her cultural environment and values such as beliefs, expectations and goals (LimaSerrano et al., 2016; Meade and Dowswell, 2015). It is a widely used measure in public 
health analysis and is key to decision-making in prevention and treatment strategies for the adoption of healthy lifestyles (Chai et al., 2010).

The concept of QoL in adolescence is important, as it has previously been linked to adverse childhood experiences, health conditions, and reduced life expectancy (Salinas-Miranda et al., 2015; Salum et al., 2014). It could also contribute to devising an age-appropriate policy tool for adolescents, as they differ from other age groups (Frisén, 2007). An understanding of the impact of BD on the QoL in adolescents could contribute to research and practice by providing data for economic evaluation studies and designing policies to discourage the excessive intake of alcohol.

However, to date, few studies (Lima-Serrano et al., 2016; Watson et al., 2017) have explored the relationship between alcohol drinking or $\mathrm{BD}$ in adolescents and HRQoL. The study carried out by Watson et al. (2017) only assessed HRQoL through the five dimensions of the EQ-5D-5L and EQ-VAS, without calculating quality-adjusted life years (QALY's), using a small number of participants, consisting of young people with substance misuse undergoing various treatments. In addition, Lima-Serrano et al. (2016) showed a lower QoL in those who consumed alcohol using a specific QoL questionnaire (KIDSCREEN).

Sociodemographic factors associated with adolescent QoL have been investigated in numerous populations in school-based cross-sectional studies, such as the European KIDSCREEN study and the International Study on Health Behaviour of School-Aged Children (HBSC study) (Moreno et al., 2016; Ravens-Sieberer et al., 2014), which used the KIDSCREEN questionnaire. However, other generic HRQoL questionnaires are available, offering great variability in both the number and characteristics of the dimensions included (Alonso et al., 1995; Pardo-Guijarro et al., 2013; Rajmil et al., 2001). 
In this regard, the EQ-5D is a widely used instrument to measure perceived wellness and health status (The EuroQol Group, 1990). Its development was motivated by economic reasons, i.e., to create a way of measuring health status to allocate health care resources (Devlin and Brooks, 2017). It is considered very important for implementing health policies due to the need to derive both cost-effectiveness and cost-utility in the programs devised by decision-makers, as concluded by Aronsson et al. (2015) in a study aimed to analyse the differences between the commonly used hypothetical UK value set and the newly introduced Swedish experience-based value set, and to evaluate the health economic implications of such differences on policy decisions.

The aim of this paper is to present a comparison between the effects on health, in terms of health-related quality of life (HRQoL), and the reduction of excessive alcohol use, with ALERTA ALCOHOL (Lima-Serrano et al., 2018), an intervention aimed at reducing BD in Spanish adolescents.

\section{Methods}

\subsection{Sample and variables}

The study population consisted of adolescents from Andalusia (a region in the south of Spain), aged 15 to 19 years, attending public schools. They were enrolled either in the fourth course of compulsory secondary education, higher secondary school, or the first course of vocational training (equivalent to 10th and 11th grades in the United States).

The sample is part of a two-arm cluster randomized controlled trial (CRCT) with an intervention group (IG) and a control group (CG) randomized at the school level to evaluate the web-based computer-tailored intervention (WBCT), ALERTA ALCOHOL 
(more information about the design of the study can be consulted in the published study protocol referred to as Lima-Serrano et al., 2018). ALERTA ALCOHOL program is compared to the absence of intervention. This program consists of providing feedback through preventive messages and personalized information about the benefits of not consuming alcohol, reducing positive attitudes towards alcohol and excessive consumption of alcohol, as well as social influence and self-efficacy. Skills and action plans are encouraged to help the student reject excessive drinking. To start the intervention, students have access to a website. This website has a section where they can create an account to obtain access to the intervention. In this account, they select their school, which determines their control or intervention group. The intervention consisted of six sessions. Session 1 consists on a reference questionnaire. Sessions 2-3 consist of a short story in which the main character wakes up after an evening in which he/she consumed alcohol excessively, and does not remember what happened. The stories take place at home (session 2), at celebrations (session 2) and in public places (session 3). Under these scenarios, the story is presented and questions and tailored messages are offered. These answers are based on the I-Change Model (De Vries, 2017, De Vries, Mesters, Van de Steeg \& Honing, 2005, De Vries, Lezwijn, Hol, \& Honing, 2005), which integrates elements of various models of social cognition and self-regulation, as well as principles of socio-ecological models, and establishes that a behavior is the result of an individual's intentions, action plans and abilities. At the session 2, when the story takes place at home, the feedback focuses on providing information about the general and individual consequences of alcohol consumption and binge drinking. At the session 3, in the second scenario, in which the story takes place in celebrations such as Christmas, weddings or festivals, the messages are directed at how to manage self-esteem and provide information about its importance. In addition, the scenario addresses issues 
related to social models. The third scenario, which is included at the session 3 too, the story takes place in public spaces and addresses issues related to social norms related to binge drinking. The questions and messages address how to resist social pressure to drink alcohol, from friends or family.In addition, in all scenarios self-efficacy is evaluated to handle these situations and specific action plans are offered depending on the answers given individually. In relation to session 4, this consists on a challenge of not consuming excessive alcohol at an upcoming event (booster session) and in the session 5 the challenge is evaluated. Finally, session 6 consists on the evaluation of the intervention. The control group only receives the baseline questionnaire and the follow-up questionnaire (sessions 1 and 6), while the intervention group performs all the sessions. Then, data of the control condition for assessing the effect in health (number of BD occasions less and quality of life) were collected in the same way that for intervention group, through an online questionnaire at baseline or period 0 (January-February) and at 4-month follow-up period or period 1 (April-May) in schools. Regard to the use of data longitudinally, we studied the difference among periods and the comparison by condition.

An initial or baseline assessment (period 0 or pre-intervention) and four-month follow-up assessment (period 1 or post-intervention) were carried out on 1247 and 612 participants, respectively. The baseline questionnaire includes demographics, alcohol use behaviours, mediator variables such as motivational determinants (social influences, selfefficacy), cost measures (health and non-health costs) and the EQ-5D-5L questionnaire to measure the HRQoL. The follow-up questionnaire includes the same items except the demographic variables.

\subsection{Dependent variables}

\subsubsection{Binge drinking reduction}


This variable was obtained from answers to the following question: "In the last 30 days, how many times did you drink 4 or more glasses of alcohol (if you are a girl) or 5 glasses or more of alcohol (if you are a boy) in one single occasion?”. The units of this measure were event counts. This question was answered in period 0 (pre-intervention) and period 1 (post-intervention). The reduction of excessive alcohol use was calculated based on the difference between the number of occasions of BD in period 1 and period 0 . Therefore, if the value of this new variable is negative, the adolescent reduced the number of occasions of BD between the two periods.

\subsubsection{Health-related quality of life}

The outcome variable was the HRQoL measured by the EQ-5D-5L questionnaire designed for the general population over 15 years of age and validated for the Spanish population (García-Gordillo et al., 2016) at baseline and at 4-month follow-up assessment. The main reason for using the EQ-5D-5L is that is a generic questionnaire to measure quality of life, suitable for carrying out an economic evaluation of the intervention accomplishing the requites for that. In addition, this questionnaire was incorporated to The Spain Health National Survey (ENSE) since 2011/12 (Ministerio de Sanidad, Servicios Sociales e Igualdad, 2014), its language and number of dimensions are more suitable for teenagers between 15 and 19 years of age than other questionnaires like the SF-36 or HUI. Moreover, the EQ-5D-5L questionnaire can be used for carrying out an economic evaluation of the ALERTA ALCOHOL program.

The EQ-5D-5L questionnaire was given to the adolescents via online at baseline and at 4 months follow up, next to the evaluation questionnaire that included the other variables mentioned above. a research technician was personally in session 1 to explain 
the development and fulfillment of such questionnaire, and the teacher was informed and advised for the development of the following sessions.

EQ utility indices were obtained from the answers provided by the adolescents to the five dimensions included in the EQ-5D-5L questionnaire (mobility, self-care, usual activities, pain/discomfort and anxiety/depression) and calculated using the EQ-5D-5L Crosswalk Index Value Calculator (García-Gordillo et al., 2016; van Hout et al., 2012). Each dimension has 5 levels (no, slight, moderate, severe and extreme problems), so a higher score indicates worse QoL. Each state is referred to in terms of a 5-digit code, of which each digit comes from the value assigned in each of the 5 dimensions. The EQ5D-5L health states score was converted into a single index value or utility index, which was used in the analysis. Moreover, this questionnaire includes an item called EQ-VAS that records the adolescents' self-rated health on a visual analogue scale between 0 and 100 , with $0=$ 'the best...' and $100=$ 'the worst health you can imagine'.

In this study, the values of the EQ utility index of 9 subjects were imputed with a value of zero because of a lack of coherence between the answer given in the item EQVAS and the answers given in the 5 items of the EQ-5D-5L (which we used to determine the EQ utility index). This index was negative, indicating that the participant would be in a worse state of health than death.

\subsection{Independent variables (related to both effect measures)}

The independent variables used for analysis about the effects of the program, both in reducing the number of occasions of BD and in HRQoL, were the same, except for the variables "predicted BD reduction" and having a partner, which were not included in the impact analysis of the program in the reduction of the $\mathrm{BD}$. 
The intervention impact was calculated by the product of the number of subjects who participated in the program and the difference in the number of $\mathrm{BD}$ occasions between the post- and pre-intervention periods. Adherence to the intervention resulted from the number of sessions completed.

The predicted BD reduction was obtained from the finite mixture model used to assess the effectiveness of the ALERTA ALCOHOL program to reduce BD, which was effective with a statistical significance of 5\%, through the prediction of the difference between the number of occasions of $\mathrm{BD}$ in period 1 (post-intervention) and period 0 (preintervention). The predicted number of $\mathrm{BD}$ occasions was controlled by period of intervention, adherence to intervention, belonging to intervention or control group, being female, age, being Spanish, having a partner, years of schooling of the mother, nuclear family, pocket money, family pressure, answering the questionnaire towards the end of the week and answering the questionnaire near the dates of local events.

Family alcohol consumption was also considered and included BD of the mother, father and siblings. This variable is categorical (0: mother, father and siblings did not binge drink moderately or more frequently; 1 : mother or father or siblings did binge drinking moderately or more frequently; 2: two members of the family (mother, father or siblings) did binge drinking moderately or more frequently; 3: mother, father and siblings did binge drinking moderately or more frequently).

Other included measurements were those related to alcohol drinking behaviour, other substance use and socioeconomic variables, including gender, age, nationality, family composition, family functionality, pocket money, economic situation at home, job situation and the educational level of the parents. Finally, the closeness between a previous event (local events such as fairs) and the completion of the questionnaires, and 
whether the participant completed the questionnaire at the beginning of the week or during the latter part of the week, were also controlled for the empirical analyses.

Other substance use (shishas or hookahs, cannabis, non-prescribed tranquilizers, sedatives or sleeping pills and prescribed tranquilizers, sedatives or sleeping pills) was measured through a self-reported question based on the ESTUDES' questionnaire (OEDA, 2018). Frequency of consumption of these substances was asked, as well as, number of shishas or hookahs a week if they answered affirmatively. Age was calculated from the difference between the date on which the subject completed the pre-intervention questionnaire and his/her birthdate. The family functionality was assessed using the family APGAR questionnaire (Bellón-Saameño et al., 1996; Gardner et al., 2001; Smilkstein, 1978; Smilkstein et al., 1982), which is a tool frequently utilized in primary care and general medicine settings, for assessing family function through a 5- item questionnaire measuring five constructs (adaptability, partnership, growth, affection and resolve). The educational level of the parents was calculated according to the number of schooling years. In relation to the variable called “Completed questionnaire near to local events", in the first session, the answers to the initial questionnaire by all the participants could be persuaded by the same event, e.g., Christmas, and in the second session, some participants were influenced by local events, such as fairs or romeries. This variable was obtained by assigning a code for the date of the event in that city that could influence the participants, as well as the date of filling in the questionnaire, and calculating the difference between the two dates.

\subsection{Statistical Analysis}

A descriptive analysis of the characteristics of the sample was carried out, and a Wilcoxon-Mann-Whitney test was used to compare the means of the scores between 
females and males, as well as between those who were $<17$ years of age and those $\geq 17$ years of age, for each dimension of the EQ-5D-5L, such as in the EQ-VAS item, according to recommendations of the EQ-5D-5L User Guide (Rabin et al., 2015).

Regarding missing data, although Rubin (1987) affirms that the multiple imputation procedures generate good results, even when the percentages of attrition reach $50 \%$, imputing data in which the attrition in one or more variables reaches percentages greater than $20 \%$ is not recommended, especially when the results are used to support the design or evaluation of public policies (Medina and Galván, 2007). For this reason, as mentioned above, we decided not to use multiple imputation and carried out the analysis with pairwise deletion.

To analyse the effects of the program on the reduction of the number of occasions of $\mathrm{BD}$, we used three regression models: negative binomial regression, two part model and finite mixture model.

We used a population-averaged panel-data model and applied the generalized estimating equations (GEE) approach (a negative binomial distribution with log link function) to analyse the effects of BD reduction on HRQoL. To estimate the parameters and perform inference with a generalized linear model, independent and identical distributions were assumed. Working with panel data (called "panel data" due to the observation of individuals during at least two instances, the baseline period and the follow-up period at 4 months), this assumption could not be taken into account due to the correlation of the observations for each individual. One possible solution is to include individual-specific random effects in the model, which can be fitted through a generalized linear mixed model (GLMM). GLMMs require some parametric assumptions. This is one of the reasons why the GEE approach was used: this model can accommodate both auto- 
correlated and non-normal data, such as the dependent variable (EQ utility index). Moreover, the GEE framework performs better than GLMMs when there are only a few observations for many of the subjects (Hubbard et al., 2010; Liang and Zeger, 1986; Stillman, 2003; Zeger et al., 1988). In this model, the outcome variable was the EQ utility index.

Statistical analysis was carried out using the statistical package Stata 15.0 version.

\subsection{Ethics approval}

The study has the approval of the Bioethical Committee of Andalusia (registration number: PI-0031-2014, 04 August 2015). Informed consent was asked of parents and students prior to participation in the study.

\section{Results}

\section{1. $\quad$ Sample characteristics}

In total, 16 schools were randomized into the IG and CG. One school in the CG withdrew its participation before the initial assessment started. In total, 1247 adolescents from 15 schools participated in the baseline questionnaire, but only 612 adolescents (response rate $49.08 \%$ ) participated in the 4-month follow-up questionnaire. At the follow-up assessment, some schools reported troubles with finding a date to administer the questionnaire, due to final exams. Moreover, vocational training students finished the course earlier than other students, and most of them were not able to complete the followup questionnaire in the classroom. Due to the high dropout rate ( $>50 \%)$, we decided not to use multiple imputation and carried out the analysis with pairwise deletion.

The average age at baseline was $16.8(\mathrm{SD}=0.02)$ years. Approximately half of the participants were female (53.01\%), 94.7\% were Spanish, and more than half of the 
sampled individuals (61.51\%) were Catholic. Family type was nuclear for $74.2 \%$ of the adolescents. In addition, in the family APGAR questionnaire, the mean was 7.6, classifying $70 \%$ of the families with normal functioning. The mean schooling years of the mothers was greater than that of the fathers, being 11.48 and 11.17 , respectively. However, more fathers (77\%) were working than mothers (65.7\%), although the difference was not statistically significant. The economic situation at home was perceived as good or very good in $62.27 \%$ of the cases.

In reference to $\mathrm{BD}, 36.64 \%$ of participants affirmed $\mathrm{BD}$ in the last month. Girls showed a lower number of occasions of BD; this difference was statistically significant. Regarding other substances, $20.4 \%$ of the participants were smokers, with an average use per week of 4.05 cigarettes $(S D=0.42)$ and/or of 0.87 shishas $(S D=0.08)$. Moreover, approximately 7\% of adolescents smoked cannabis.

Comparing the adolescents in both groups, the IG and CG significantly differed from each other in various characteristics. Adolescents in the IG were older; their mothers had fewer schooling years, their fathers were more likely to be working; their families had economic difficulties; their mothers were less moderate or frequent drinkers of alcohol; their best friend binge drank moderately or more frequently in a major proportion of cases, and they consumed fewer not-prescribed tranquilisers, sedatives or sleeping pills. Characteristics of both intervention and control group in period 0 and period 1 related to outcome measures, adherence to intervention and other variables are presented in the table 1 . This shows that the adolescents who received the intervention reduced the number of BD occasions more than the adolescents who belonged to the control group, although this difference was not statistically significant. Related to quality of life, the control group starts from a lower perception of the quality of life than the intervention 
group, although in the follow-up assessment the quality of life improves in both groups, reaching a very similar score.

Regarding the dimensions of the EQ-5D-5L questionnaire, more than $90 \%$ of participants reported level 1 (no problems) in the mobility, self-care and usual activity dimensions. Nevertheless, in the pain/discomfort and anxiety/depression dimensions, the percentage of answers was distributed between level 1 and level 2 (fewer problems) for the total sample. In pain/discomfort dimension, approximately eight in ten (78.03\%) adolescents reported level 1 and $16.6 \%$ of participants reported level 2 . In anxiety/depression dimension, the distribution of answers between level 1 and 2 was similar to pain/discomfort dimension, reporting level 1 approximately eight in ten (76.68\%) adolescents and level 2 the $15.43 \%$ of participants.

In relation to the mean and standard deviation of the values for each dimension of the EQ-5D-5L in the total sample, the dimension with the worst score was 'anxiety/depression' followed by 'pain/discomfort', with an average of 1.35 and 1.29, respectively, in which the difference by gender was statistically significant, with the girls obtaining worse scores in both dimensions, whereas in relation to the 'mobility' and 'selfcare' dimensions, girls reported better scores than boys. This difference was significant by gender in all dimensions except in 'usual activity' and 'mobility'. Males reported no having problems (level 1) in pain/discomfort and anxiety/depression in a proportion of 84.16\% and 81.39\%, respectively. They also reported few problems in (level 2) in a proportion of $11.49 \%$ and $12.20 \%$, respectively. In contrast, females reported no having problems in pain/discomfort and anxiety/depression dimensions in a proportion of $72.75 \%$ and $72.63 \%$, respectively, and they reported having few problems in a proportion of $20.99 \%$ and $18.21 \%$, respectively. This means that girls had more problems than boys in relation to these health problems mentioned above. Regarding age, the only dimension 
that was statistically significant was 'mobility' in girls, reporting a worse score for those under 17 years of age. Regarding the adolescent's self-rated health or EQ-VAS, girls reported a worse health state than boys, with a mean score of $83.14(\mathrm{SD}=20.91)$ and a mean score of 86.47 ( $S D=18.17)$, respectively. Furthermore, this difference was also observed by age groups. The younger girls ( $<17$ years old) scored an average of 83.66 ( $S D=19.79)$ while boys scored an average of $87.27(S D=16.83)$. Similarly, these findings were found in the older group ( $\geq 17$ years old, in which girls scored an average of 82.13 $(\mathrm{SD}=22.89)$ and boys scored an average of 84.85 (SD=20.59). With respect to EQ-5D5L index values, the mean score was $0.94(S D=0.13)$ in the whole sample, being 0.93 $(\mathrm{SD}=0.11)$ in girls and $0.94(\mathrm{SD}=0.15)$ in boys; this was not statistically significant $(\mathrm{p}=0.07)$. The Shapiro-Wilk and Shapiro-France tests showed that EQ Utility Index data were not distributed normally for total sample $\left(\mathrm{W}=0.719, \mathrm{p}=0.00000 ; \mathrm{W}^{\prime}=0.750\right.$, $\mathrm{p}=0.00001$ ) or for subgroup (intervention group: $\mathrm{W}=0.69882, \mathrm{p}=0.00000, \mathrm{~W}^{\prime}=0.76256$, $\mathrm{p}=0.00001$; control group: $\mathrm{W}=0.67830, \mathrm{p}=0.00000, \mathrm{~W}^{\prime}=0.73796, \mathrm{p}=0.00001$ ).

\subsection{Dealing with missing data}

Table 2 shows the baseline characteristics of the sample according to the pattern of missing data by condition. It seems important to highlight that those who did not answer the post-intervention questionnaire were older, their fathers' and mothers' schooling years were lower, the current job situation of the mother was worse, and there was a worse economic situation at home and higher weekly pocket money. Moreover, in relation to alcohol use, those who did not answer the post-intervention questionnaire reported a higher number of occasions of BD; they also consumed a greater amount of alcohol during the prior week; their friends consumed alcohol more frequently, and their best friend consumed alcohol more frequently. Finally, a higher proportion of those who 
did not answer the questionnaire in the post-intervention period were cigarette smokers. The resultant differences were statistically significant.

\subsection{Effects on health of a program to reduce $B D$ in adolescents}

We will present the data of the two effects of the intervention carried out. First, we present the effect data in the BD reduction, and second, we present the effect data on HRQoL.

Table 3 shows the results for the three different regression models used for measuring the intervention effect on the reduction of the number of occasions of BD (the two part model showed the highest performance level by far regarding statistical measures), as well as the results for the fitted population-averaged panel-data model using a GEE approach for measuring the intervention impact on HRQoL.

The effectiveness of the ALERTA ALCOHOL program to reduce the probability of BD was statistically significant, such as a higher adherence to the program (a higher number of sessions filled), which showed a reduction in the number of occasions of BD (see Table 3). This means, in accordance with the two part model, that those who filled more sessions of program, reduced the number of BD occasions. Furthermore, as table 1 shows, the reduction in the follow-up period of the number of BD occasions was greater in the intervention group than in the control group, although this difference was not statistically significant.

However, in relation to the health benefits measured in terms of HRQoL at the 4month follow-up, the pattern was different. The ALERTA ALCOHOL program was not shown to be significantly effective in increasing the HRQoL in adolescents who reduced the number of occasions of BD and had received the intervention. However, it was shown that those who reduced the number of occasions of BD perceived a higher HRQoL, as did 
those who had a greater adherence to the program. Moreover, this highlights that a higher predicted BD reduction results in an increase of HRQoL. This fact was found in the adjusted model (model 2) of the fitted population-averaged panel-data models with the GEE approach.

\subsection{Socioeconomic variables associated with HRQoL}

In Table 3, we also show the results of our panel data in relation to associated variables of HRQoL in adolescents through a fitted population-averaged panel-data model with the GEE approach using a negative binomial distribution. Other variables were not included to avoid collinearity. The variables that resulted in statistically significant effects were the participant's age, having a partner and family alcohol consumption, which negatively affected HRQoL; those who were older, had a partner and whose family consumed alcohol frequently, perceived a worse HRQoL.

\section{Discussion}

The aim of this study was to compare and assess the effects on health in terms of the reduction of binge drinking and health-related quality of life in adolescents between 15 and 19 years of age enrolled in public high schools who were involved in CRCT to evaluate the ALERTA ALCOHOL program. The main findings showed that although the program was effective in reducing $\mathrm{BD}$ in a period of 4 months, it seems that the effects on HRQoL require a longer period to appear. Regarding the findings related to HRQoL, the adjusted fitted population-averaged panel-data model with the GEE approach was more explicit due to the inclusion of other variables pertaining to HRQoL and BD in this sample. Although there are several studies (Luquiens et al., 2016; Meade and Dowswell, 2016) that analyse the relationship between BD and HRQoL in adolescence, we did not find any study that assessed the effects of an intervention for BD reduction on HRQoL in 
adolescents. The variables related to HRQoL increase were $\mathrm{BD}$ reduction, higher adherence to the ALERTA ALCOHOL program, being older, having a partner and higher family alcohol consumption.

Regarding scores for each dimension of the EQ-5D-5L, statistically significant differences were found between girls and boys in 'pain/discomfort' and ‘anxiety/depression’, with boys reporting a higher score than girls. However, boys had a lower score in the other three dimensions compared to girls, contrary to what was found by Meade and Dowswell (2015).

Our results are similar to those found by Tosé Agathao et al. (2018), in which girls showed higher values than boys in the majority of items of the used tool. In the study of Hoeymans et al. (2005) in the Dutch population, researchers found slightly lower mean scores on the EQ5D index value. The percentages of respondents reporting a problem in each EuroQoL dimension by gender and age were very similar to our sample, highlighting the mobility and pain/discomfort dimensions.

In relation to age, similar to Bradford et al. (2002) and Meade and Dowswell (2015), we found that the HRQoL of older adolescents was more negative than middleaged adolescents.

Regarding findings related to lower HRQoL in those who have a partner, literature is scarce. The Spanish National Health Survey 2011-2012 (2016) was the only study conducted in Spanish persons at least 15 years old, in which their HRQoL was measured through the EQ-5D-5L (accounting for the sociodemographic variable, marital status). Although the response categories of this variable differ from our study, the researchers found that single individuals reported a better QoL than those who were married or separated/divorced. In our study, those who had a partner also had a worse QoL. 
In other respects, having a higher pocket money is related to a lower HRQoL and could be associated with higher substance use (Díaz-Geada et al., 2018). For example, in our study, a reduction of the number of occasions of BD translated into a higher QoL; this difference was significant.

Finally, in relation to family alcohol consumption, Dussaillant and Fernandez (2014) assessed the degree to which relationships with heavy drinkers affected the health and well-being in the Chilean adult population and how this compares with previously published analyses in an Australian sample. They found that heavy drinkers inside the household displayed a greater negative association with EQ-5D. These results are similar to those found in our study.

\subsection{Strengths and limitations}

The main limitation of our study is that the questionnaire was self-reported. This could have caused the students to answer in a manner they deemed socially acceptable, although confidentiality was guaranteed during completion of the questionnaire. Another limitation could be missing data from the post-test, which significantly reduced the data collected for the perception of HRQoL, such as that from the EQ-5D-5L, which is a generic instrument. The main cause of missing data was completion of classes sooner in the vocational training students (before the other participants). This high dropout rate prevented us from using multiple imputation. High attrition could affect the outcomes of analysis, but it is known that high attrition rates are common in eHealth interventions (de Vries et al., 2012; Kohl et al., 2013). The impact of randomization at the school level could have negatively affected to response rate due to dropping out during and after the intervention of whole schools. The differences in the characteristics of participants who did not fill the sessions, which includes the program, or the follow-up questionnaire (adolescents who dropped out were older, his/her father studied during a lower number 
of years, were engaged to binge drinking more frequently, had a higher weekly pocket money,...), in contrast to those who did, can be explained in part by the dropout of the whole school. Similarly, according to the characteristics of participants at baseline with missing and no missing values, those youths who had missing values in the postintervention questionnaire were overall from more adverse backgrounds and had more BD. Those youths that have problematic behaviour usually absent more from school (Substance Abuse and Mental Health Services Administration, 2012), which could impact in attrition given the different sessions of the program were delivered at school level. Other explanation for that attrition could be the possible over-confronting nature of the program, which distances the most problematic adolescents who really need to correct their consumption. Hence, the potential gain from the intervention could be higher for those who missed the program. However, given their more adverse background, the probability of "success" of the intervention is probably lower. Therefore, the net effect is unclear, and consequently, the selection bias could go both ways. Another limitation could be considered as is that data about psychiatric comorbidities were not collected because we would have needed to compare the data provided by adolescents with those registered in the national health system, and this was not possible due to lack of resources. Another reason why we did not collect this data was the objective of the ALERT ALCOHOL intervention that is aimed at universal prevention, that is, healthy subjects a priori. However, it would have been interesting to know the psychiatric comorbidities because these disorders are common among adolescents with substance use disorders and it has been shown that those with a history of anxiety and depressive disorders have twice the risk of later developing substance use (Christie et al., 1998, In; Deas, 2006). In addition, completing the questionnaire much later than last weekend could have resulted in participants forgetting information on how much they drank on the previous weekend; 
this could also have caused disinterest. Furthermore, the lack of impact of the ALERTA ALCOHOL program on HRQoL could be due to the short follow-up period, which was carried out 4 months after the start of the intervention. Thus, it seems necessary to conduct a long-term evaluation, as mentioned above. However, this fact could be considered a strength of this study, given the finding in relation to adherence, predicted BD reduction and participants' HRQoL in the short term. Moreover, this study could contribute to knowledge about the determinants of HRQoL in adolescence; few studies have examined HRQoL measured through the EQ-5D-5L in the adolescent population, without the presence of a disease (Dussaillant and Fernández, 2014).

\subsection{Conclusions}

In conclusion, a higher adherence to a WBCT intervention to prevent BD in adolescents has a positive effect on decreasing the number of occasions of BD in adolescents as well as on increasing participants' HRQoL, although this second effect is very small due to the short follow-up time. This fact is quite important and should be assessed over a long time period to corroborate the results and to be able to translate the findings into health policy for the adolescent population. 


\section{Consent for publication}

The current work has not been published previously, and it is not under consideration for publication elsewhere. The publication is approved by all authors. If accepted, it will not be published elsewhere in the same form, in English or in any other language, including electronically, without the written consent of the copyright holder. 


\section{References}

Alonso, J., Prieto, L., Anto, J.M., 1995. La versión española del SF-36 Health Survey (Cuestionario de Salud SF-36): Un instrumento para la medida de los resultados clínicos. [The Spanish version of the SF-36 Health Survey: An instrument for the measurement of clinical outcomes]. Med Clín (Barc.). 104, 771-776.

Anderson, P, 2014. Binge drinking and Europe. London: Institute of Alcohol Studies; 2007. Accessed 2 July 2018. http://www.drugsandalcohol. ie/6353/1/38364088.pdf

Aronsson, M., Husberg, M., Kalkan, A., Eckard, N., Alwin, J., 2015. Differences between hypothetical and experience-based value sets for EQ-5D used in Sweden: Implications for decision-makers. Scand J Public Health. 43, 848-854. https://doi.org/10.1177/1403494815596910

Bellón Saameño, J. A., Delgado Sánchez, A., Luna del Castillo, J. D., Lardelli Claret, P., 1996. [Validity and reliability of the family Apgar family function test]. Aten Primaria. 18(6), 289-96. http://www.ncbi.nlm.nih.gov/pubmed/8983381

Bradford, R., Rutherford, D., John, A., 2002. Quality of life in young people: Ratings and factor structure of the quality of life profile - adolescent version. J Adolesc. 25, 261-274.

Caamaño-Isorna, F., Moure-Rodríguez, L., Doallo, S., Corral, M., Rodríguez Holguín, S., Cadaveira, F., 2017. Heavy episodic drinking and alcohol-related injuries: An open cohort study among college students. Accid Anal Prev. 100, 23-29. 
Calafat Far, A., 2007. El abuso de alcohol de los jóvenes en España. [The alcohol abuse by young people in Spain]. Adicciones. 19(3), 217-223. doi:10.20882/adicciones.302

Chai, W., Nigg, C.R., Pagano, I.S., Motl, R.W., Horwath, C., Dishman, R.K., 2010. Associations of quality of life with PA, fruit and vegetable consumption, and physical inactivity in a free living, multi-ethnic population in Hawaii: A longitudinal study. Int J Behav Nutr Phys Act. 7(83). doi:10.1186/1479-5868-783.

Christie, K. A., Burke, J. D., Regier, D.A., et al., 1998. Epidemiologic evidence for early onset of mental disorders and higher risk of drug abuse in young adults. In Deas, D., 2006. Adolescent Substance Abuse and Psychiatric Comorbidities. J Clin Psychiatry. 67 (Suppl 7): 18-23.

Cortés, M.T., Espejo, B., Giménez, J.A., 2007. Características que definen el fenómeno del botellón en universitarios y adolescentes. [Characteristics that define the bottle phenomenon in university students and adolescents]. Adicciones. 19, 357-372.

de Vries, H., 2017. An integrated approach for understanding health behavior; the Ichange model as an example. Psychol Behav Sci Int J. 2(2). Doi: 10.19080/PBSIJ.2017.02.555585.

de Vries, H., Mesters, I., Van de Steeg, H., Honing, C., 2005. The general public’s information needs and perceptions regarding hereditary cancer: an application of the integrated change model. Patient Educ Couns. 56(2), 154-165. doi: 10.1016/j.pec.2004.01.002. 
de Vries, H., Lezwijn, J., Hol, M., Honing, C., 2005. Skin cancer prevention: behavior and motives of Dutch adolescents. Eur J Cancer Prev. 14(1):39-50. doi: 10.1097/00008469-200502000-00006.

de Vries, H., Logister, M., Krekels, G., Klaasse, F., Servranckx, V., van Osch, L., 2012. Internet based computer tailored feedback on sunscreen use. J Med Internet Res. 14(2), e48. doi: 10.2196/jmir.1902.http://www.jmir.org/2012/2/e48/

Devlin, N., Brooks, R., 2017. EQ-5D and the EuroQol group: Past, present and future. Appl Health Econ Health Policy. 15, 127-137.

Díaz-Geada, A., Busto-Miramontes, A., Caamaño-Isorna, F., 2018. Alcohol, tobacco and cannabis consumption in adolescents from a multicultural population (Burela, Lugo). Adicciones. 30(4), 264-270. doi: 10.20882/adicciones.915

Dussaillant, F., Fernandez, M., 2014. Alcohol's harm to others' well-being and health: A comparison between Chile and Australia. Alcohol Alcohol. 50(3), 346-351. doi:10.1093/alcalc/agv002

ESPAD Group, 2016. ESPAD Report 2015: Results from the European School Survey Project on Alcohol and Other Drugs. Publications Office of the Euroepan Union, Luxembourg. https://doi.org/10.2810/289970

Frisén, A., 2007. Measuring health-related quality of life in adolescence. Acta Paediatr. 96, 963-968.

García-Gordillo, M.A., Adsuar, J.C., Olivares, P.R., 2016. Normative values of EQ-5D5L: In a Spanish representative population sample from Spanish Health Survey, 2011. Qual Life Res. 25(5), 1313-1321. 
Grant, B.F., Stinson, F.S., Harford, T.C., 2001. Age at onset of alcohol use and DSM-IV alcohol abuse and dependence: A 12-year follow-up. J Subst Abuse. 13, 493-504.

Hilton, M.E., 1987. Demographic characteristics and the frequency of heavy drinking as predictors of self-reported drinking problems. Br J Addic. 82, 913-925.

Hoeymans, N., van Lindert, H., and Westert, G.P., 2005. The health status of the Dutch population as assessed by the EQ-6D. Qual Life Res. 14(3), 655-663.

Hubbard, A.E., Ahern, J., Fleischer, N.L., Van der Laan, M., Lippman, S.A., Jewell, N., Bruckner, T., Satariano, W.A., 2010. To GEE or not to GEE: Comparing population average and mixed models for estimating the associations between neighborhood risk factors and health. Epidemiology. 21(4), 467-474. doi:10.1097/EDE.0b013e3181caeb90

Kohl, L.F., Crutzen, R., de Vries, N.K., 2013. Online prevention aimed at lifestyle behaviors: a systematic review of reviews. J Med Internet Res. 15(7), e146. http://doi.org/10.2196/jmir.2665

Lammers, J., Goossens, F., Conrod, P., Engels, R., Wiers, R. W., Kleinjan, M. (2017). Effectiveness of a selective alcohol prevention program targeting personality risk factors: Results of interaction analyses. Addict Behav. 71, 82-88. https://doi.org/10.1016/J.ADDBEH.2017.02.030

Liang, K-Y., Zeger, S.L., 1986. Longitudinal data analysis using generalized linear models. Biometrika. 73(1), 13-22.

Lima-Serrano, M., Martínez-Montilla, J.M., Guerra-Martín, M.D., Vargas-Martínez, A.M., Lima-Rodríguez, J., 2016. Factores relacionados con la calidad de vida en 
la adolescencia. [Factors related to the quality of life in adolescence]. Gac sanit. 32(1), 68-71.

Lima-Serrano, M., Martínez-Montilla, J.M., Lima-Rodríguez, J.S., Mercken, L., de Vries, H., 2018. Design, implementation and evaluation of a web-based computertailored intervention to prevent binge drinking in adolescents: Study protocol. BMC Public Health. 18(1), 449. doi:10.1186/s12889-018-5346-4

López-Caneda, E., Mota, N., Crego, A., Velasquez, T., Corral, M., Rodríguez Holguín, S., Cadaveira, F., 2014. Anomalías neurocognitivas asociadas al consumo intensivo de alcohol (binge drinking) en jóvenes y adolescentes: una revisión. [Neurocognitive abnormalities associated with heavy drinking (binge drinking) in young people and adolescents: a review]. Adicciones. 26, 334-359.

Luquiens, A., Falissard, B., Aubin, H. J., 2016. Students worry about the impact of alcohol on quality of life: Roles of frequency of binge drinking and drinker selfconcept. Drug and Alcohol Dependence. 167, 42-48. https://doi.org/10.1016/j.drugalcdep.2016.07.031

Mäkelä, K., Mustonen, H., 2000. Relationships of drinking behaviour, gender and age with reported negative and positive experiences related to drinking. Addiction. 95(5), 727-736

Meade, T., Dowswell, E., 2015. Health-related quality of life in a sample of Australian adolescents: Gender and age comparison. Qual Life Res. 24, 2933-2938. 
Meade, T., Dowswell E., 2016. Adolescents’ health-related quality of life (HRQoL) changes over time: a three year longitudinal study. Health Qual Life Outcomes. 14, 14. doi: 10.1186/s12955-016-0415-9.

Medina, F., Galván, M., 2007. Imputación de datos: teoría y práctica. [Data imputation: theory and practice]. Statistics and Economic Projections Division.

Midanik, L.T., Clark, W.B., 1995. Drinking-related problems in the United States: description and trends, 1984-1990. J Stud Alcohol. 56(4), 395-402

Ministerio de Sanidad, Servicios Sociales e Igualdad, 2014. Encuesta Nacional de Salud. España 2011/12. Calidad de vida relacionada con la salud en adultos: EQ-5D-5L. Series Informes monográficos $n^{0} 3$. Madrid: Ministerio de Sanidad, Servicios Sociales e Igualdad.

Mohamed, S., Ajmal, M., 2015. Multivariate analysis of binge drinking in young adult population: Data analysis of the 2007 Survey of Lifestyle, Attitude and Nutrition in Ireland. Psychiatry Clin Neurosci. 69(8), 483-488.

Moreno, C., Ramos, P., Rivera, F., Jiménez-Iglesias, A., García-Moya, I., SánchezQueija, I., Moreno-Maldonado, C., Paniagua, C., Villafuerte-Díaz, A., Morgan, A., 2016. Los adolescentes españoles: estilos de vida, salud, ajuste psicológico y relaciones en sus contextos de desarrollo. Resultados del Estudio HBSC-2014 en España. [Spanish adolescents: lifestyles, health, psychological adjustment and relationships in their development contexts. Results of the HBSC-2014 Study in Spain]. Ministerio de Sanidad, Servicios Sociales e Igualdad. Accessed 2 July 2018.

https://www.mscbs.gob.es/profesionales/saludPublica/prevPromocion/promocio 
n/saludJovenes/estudioHBSC/docs/HBSC2014/HBSC2014_ResultadosEstudio.p

df

Observatorio Español de las Drogas y las Adicciones (OEDA) (2018). Encuesta sobre el uso de drogas en enseñanzas secundarias en España (ESTUDES) 2016-2017. Madrid, España: Ministerio de Sanidad, Consumo y Bienestar Social. Accessed 29 May 2019. http://www.pnsd.msssi.gob.es/profesionales/sistemasInformacion/sistemaInform acion/pdf/2016_2017_ESTUDES.pdf

Pardo-Guijarro, M.J., Woll, B., Moya-Martínez, P., Martínez-Andrés, M., CortésRamírez, E.E., Martínez-Vizcaíno, V., 2013. Validity and reliability of the Spanish sign language version of the KIDSCREEN-27 health-related quality of life questionnaire for use in deaf children and adolescents. Gac Sanit. 27(4), 318324.

Plan Nacional sobre Drogas, 2018. Encuesta sobre el uso de drogas en enseñanzas secundarias en España (ESTUDES) 2016-2017. [National Plan on Drugs. Survey on the use of drugs in secondary education in Spain 2016-2017]. Madrid, España: Delegación del Gobierno para el Plan Nacional sobre Drogas, Ministerio de Sanidad, Servicios Sociales e Igualdad.

Rabin, R., Oemar, M., Oppe, M., Janssen, B., Herdman, M., 2015. EQ-5D-5L user guide. Basic Inf how to use EQ-5D-5L Instrum. Accessed 28 April 2018. http://www.euroqol.org/fileadmin/user_upload/Documenten/PDF/Folders_Flyer s/EQ-5D-5L_UserGuide_2015.pdf 
Rajmil, L., Estrada, M.D., Herdman, M., Serra-Sutton, V., Alonso, J., 2001. Calidad de vida relacionada con la salud (CVRS) en la infancia y la adolescencia: Revision de la bibliografía y de los instrumentos adaptados en España. [Health-related quality of life (HRQOL) in childhood and adolescence: Review of the literature and adapted instruments in Spain]. Gac Sanit. 15(Supl. 4), 34-43.

Ravens-Sieberer, U., Herdman, M., Devine, J., Otto, C., Bullinger, M., Rose, M., Klasen, F., 2014. The European KIDSCREEN approach to measure quality of life and well-being in children: Development, current application, and future advances. Qual Life Res. 23, 791-803.

Rubin, 1987. Multiple imputation for non-response in surveys. New York, Wiley.

Salinas-Miranda, A.A., Salemi, J.L., King, L.M., Baldwin, J.A., Berry, E.L., Austin, D.A., Scarborough, K., Spooner, K.K., Zoorob, R.J., Salihu, H.M., 2015. Adverse childhood experiences and health related quality of life in adulthood: Revelations from a community needs assessment. Health Qual Life Outcomes. 13, 123. doi: 10.1186/s12955-015-0323-4

Salum, G.A., De Sousa, D.A., Bosa, V.L., Schuch, I., Goldani, M., Isolan, L.R., Teche, S.P., Fleck, M.P., Rohde, L.A., Manfro, G.G., 2014. Internalizing disorders and quality of life in adolescence: Evidence for independent associations. Rev Bras Psiquiatr. 36 (4), 305-312. doi: 10.1590/1516-4446-2014-1362

Smilkstein, G., 1978. The Family APGAR: a proposal for a family function test and its use by physicians. J Fam Pract. 6,1231-1239. 
Smilkstein, G., Ashworth, C., Montano, D., 1982. Validity and reliability of the Family APGAR as a test of family function. J Fam Pract. 15, 303-311.

Spoelder, M., Tsutsui, K.T., Lesscher, H.M.B., Vanderschuren, L.J.M.J., Clark, J.J., 2015. Adolescent alcohol exposure amplifies the incentive value of rewardpredictive cues through potentiation of phasic dopamine signaling. Neuropsychopharmacology. 40(13), 2873-2885. doi:10.1038/npp.2015.139

Stillman, S., 2003. Review of generalized estimating equations by Hardin and Hilbe. Stata Journal. 3(2), 208-210.

Substance Abuse and Mental Health Services Administration. (2012). Comparing and Evaluating Youth Substance Use Estimates from the National Survey on Drug Use and Health and Other Surveys. Rockville (MD): Substance Abuse and Mental Health Services Administration (US). Retrieved from https://www.ncbi.nlm.nih.gov/books/NBK533887/

The EuroQol Group, 1990. EuroQol-a new facility for the measurement of health-related quality of life. Health Policy. 16(3), 199-208.

Tosé Agathao, B., Eduardo Reichenheim, M., Leite de Moraes, C., 2018. Health-related quality of life of adolescent students. Cien Saude Colet. 23(2), 659-668. doi:10.1590/1413-81232018232.27572016.

US Surgeon General, 2007. Surgeon General's call to action to prevent and reduce underage drinking. Washington (DC): Department of Health and Human Services, Office of the Surgeon General. 
van Hout, B., Janssen, M.F., Feng, Y.S., Kohlmann, T., Busschbach, J., Golicki, D., Lloyd, A., Scalone, L., Kind, P., Pickard, A.S., 2012. Interim scoring for the EQ5D-5L: Mapping the EQ-5D-5L to EQ-5D-3L value sets. Value Health. 15(5), 708-715.

Watson, L., Toner, P., Day, E., Back, D., Brady, L.M., Fairhurst, C., Renwick, C., Templeton, L., Akhtar, S., Lloyd, C., Li, J., Cocks, K., Ambegaokar, S., Parrott, S., McArdle, P., Gilvarry, E., Copello, A., 2017. Youth social behaviour and network therapy (Y-SBNT): Adaptation of a family and social network intervention for young people who misuse alcohol and drugs - a randomised controlled feasibility trial. Health Technol Assess. 21(15), 1-260. doi: 10.3310/hta21150.

World Health Organization (WHO), 2014. Global status report on alcohol and health. $\begin{array}{llll}\text { Accessed } & 2 & \text { July }\end{array}$ http://www.who.int/substance_abuse/publications/global_alcohol_report/en/

Zeger, S.L., Liang, K-Y., Albert, P.S., 1988. Models for longitudinal data : A generalized estimating equation approach. Biometrics. 44(4), 1049-1060. 


\section{Tables}

Table 1. Outcome measures and characteristics of intervention and control group in both period 0 (pre-intervention) and period 1 (post-intervention).

\begin{tabular}{|c|c|c|c|c|}
\hline \multirow{2}{*}{$\begin{array}{l}\text { Variables } \\
\text { Sociodemographic variables }\end{array}$} & \multicolumn{2}{|c|}{ Intervention group } & \multicolumn{2}{|l|}{ Control group } \\
\hline & $\begin{array}{l}\text { Pre- } \\
\text { intervention } \\
(n=742)\end{array}$ & $\begin{array}{l}\text { Post- } \\
\text { intervention } \\
(n=349)\end{array}$ & $\begin{array}{l}\text { Pre-intervention } \\
(n=505)\end{array}$ & $\begin{array}{l}\text { Post- } \\
\text { intervention } \\
(n=263)\end{array}$ \\
\hline Being female & \multicolumn{2}{|c|}{$0.535(0.50)$} & \multicolumn{2}{|c|}{$0.523(0.50)$} \\
\hline Age & \multicolumn{2}{|c|}{$16.866(1.06)$} & \multicolumn{2}{|c|}{$16.681(1.04)^{* * *}$} \\
\hline Being Spanish & \multicolumn{2}{|c|}{$0.954(0.21)$} & \multicolumn{2}{|c|}{$0.936(0.24)$} \\
\hline Partner & \multicolumn{2}{|c|}{$0.381(0.49)$} & \multicolumn{2}{|c|}{$0.336(0.47)$} \\
\hline Mother's schooling years & \multicolumn{2}{|c|}{$20.390(27.07)$} & \multicolumn{2}{|c|}{$22.683(29.00)$} \\
\hline Nuclear family composition & \multicolumn{2}{|c|}{$0.741(0.44)$} & \multicolumn{2}{|c|}{$0.743(0.44)$} \\
\hline Pocket money (weekly) & \multicolumn{2}{|c|}{$10.610(9.08)$} & \multicolumn{2}{|c|}{$11.206(9.61)$} \\
\hline Good economic situation at home & \multicolumn{2}{|c|}{$0.449(0.50)$} & \multicolumn{2}{|c|}{$0.491(0.50)$} \\
\hline \multicolumn{5}{|l|}{ Some outcome variables } \\
\hline $\begin{array}{l}\text { Adherence to intervention (number of sessions } \\
\text { completed) }\end{array}$ & \multicolumn{2}{|c|}{$2.604(1.24)$} & \multicolumn{2}{|c|}{$1.523(0.50)^{* * *}$} \\
\hline EQ Utility Index & $0.942(0.11)$ & $0.944(0.14)$ & $0.925(0.15)^{* *}$ & $0.94(0.13)$ \\
\hline $\begin{array}{l}\text { Completed questionnaire later than last } \\
\text { weekend }\end{array}$ & $0.695(0.46)$ & $0.782(0.41)$ & $0.681(0.47)$ & $0.433(0.50)^{* * *}$ \\
\hline $\begin{array}{l}\text { Completed questionnaire near the dates of } \\
\text { local events }\end{array}$ & 34.782 (10.59) & $12.063(11.24)$ & $36.891(7.84)^{* * *}$ & $20.179(9.12)^{* * *}$ \\
\hline \multicolumn{5}{|l|}{ Alcohol consumption and BD } \\
\hline Number of occasions of BD & $1.125(1.90)$ & $0.876(1.74)$ & $1.081(1.91)$ & $1.065(2.15)$ \\
\hline Alcohol use on last weekend & $0.235(0.42)$ & $0.112(0.32)$ & $0.216(0.41)$ & $0.113(0.32)$ \\
\hline Frequency alcohol use in public outdoor places & $1.194(2.28)$ & $0.966(2.24)$ & $1.108(2.20)$ & $0.712(1.55)$ \\
\hline in parties or celebrations & $1.543(2.57)$ & $1.114(2.22)$ & $1.481(2.38)$ & $1.094(2.02)$ \\
\hline at home or someone else's home & $0.960(2.07)$ & $0.615(1.44)$ & $1.104(2.28)$ & $0.727(1.66)$ \\
\hline $\begin{array}{l}\text { Glasses of alcohol consumed in outdoor public } \\
\text { places }\end{array}$ & $1.640(2.14)$ & $1.26(2.056)$ & $1.478(2.16)$ & $1.273(2.20)$ \\
\hline in parties or celebrations & $2.49282 .68)$ & $1.980(2.33)$ & $2.518(2.61)$ & $2.05(2.61)$ \\
\hline at home or someone else's home & $1.325(1.98)$ & $0.983(1.83)$ & $1.467(2.11)$ & $1.358(2.22)^{* *}$ \\
\hline $\begin{array}{l}\text { Mother consumes alcohol moderately/more } \\
\text { frequently }\end{array}$ & $0.233(0.42)$ & $0.113(0.32)$ & $0.281(0.45)^{*}$ & $0.121(0.33)$ \\
\hline \multirow[b]{6}{*}{ Mother binge drinks more frequently } & $0.418(0.49)$ & $0.181(0.39)$ & $0.444(0.50)$ & $0.192(0.39)$ \\
\hline & $0.225(0.42)$ & $0.082(0.28)$ & $0.240(0.43)$ & $0.115(0.32)^{*}$ \\
\hline & $0.179(0.38)$ & $0.066(0.25)$ & $0.152(0.36)$ & $0.069(0.25)$ \\
\hline & $0.814(0.39)$ & $0.342(0.48)$ & $0.818(0.39)$ & $0.398(0.49)^{* *}$ \\
\hline & $0.584(0.49)$ & $0.249(0.43)$ & $0.543(0.50)$ & $0.248(0.43)$ \\
\hline & $0.051(0.22)$ & $0.027(0.16)$ & $0.073(0.26)$ & $0.022(0.15)$ \\
\hline Father & $0.156(0.36)$ & $0.067(0.25)$ & $0.160(0.37)$ & $0.044(0.20)^{*}$ \\
\hline Siblings & $0.128(0.33)$ & $0.053(0.22)$ & $0.150(0.36)$ & $0.053(0.23)$ \\
\hline Partner & $0.119(0.32)$ & $0.044(0.21)$ & $0.111(0.31)$ & $0.057(0.23)$ \\
\hline Friends & $0.683(0.47)$ & $0.272(0.45)$ & $0.640(0.48)$ & $0.309(0.46)$ \\
\hline Best friend & $0.446(0.50)$ & $0.190(0.39)$ & $0.388(0.49)^{* *}$ & $0.196(0.40)$ \\
\hline $\begin{array}{l}\text { Family alcohol consumption (BD of the } \\
\text { mother, father and siblings) }\end{array}$ & $0.336(0.63)$ & $0.147(0.47)$ & $0.491(0.66)$ & $0.119(0.39)$ \\
\hline Other consumptions & & & & \\
\hline
\end{tabular}




\begin{tabular}{|c|c|c|c|c|}
\hline Being a smoker & $0.224(0.42)$ & $0.168(0.38)$ & $0.234(0.42)$ & $0.196(0.40)$ \\
\hline Number of cigarettes a week & 4.361 (13.92) & $4.257(16.35)$ & $4.047(15.07)$ & $3.333(12.37)$ \\
\hline User of cannabis & $0.061(0.24)$ & $0.053(0.22)$ & $0.085(0.28)^{*}$ & $0.079(0.27)^{*}$ \\
\hline Number of shishas or hookahs a week & $0.821(2.49)$ & $0.652(1.68)$ & $1.050(2.77)$ & $1.053(3.44)^{*}$ \\
\hline $\begin{array}{l}\text { Prescribed tranquilisers, sedatives or sleeping } \\
\text { pills }\end{array}$ & $0.019(0.14)$ & $0.026(0.16)$ & $0.032(0.18)$ & $0.028(0.16)$ \\
\hline $\begin{array}{l}\text { Non-prescribed tranquilisers, sedatives or } \\
\text { sleeping pills }\end{array}$ & $0.012(0.11)$ & $0.019(0.14)$ & $0.028(0.16)^{* *}$ & $0.026(0.16)$ \\
\hline
\end{tabular}

${ }^{a}$ We show the average values and standard deviations in brackets. ${ }^{* *}, * *$ and $*$ represent statistically significant differences at $1 \%$, $5 \%$ and $10 \%$ between values of variables in intervention and control group (2nd and 4th column) in pre-intervention or period 0.

${ }^{\mathrm{b}}$ We show the average values and standard deviations in brackets. ${ }^{* * *}$, ** and * represent statistically significant differences at $1 \%$, $5 \%$ and $10 \%$ between values of variables in intervention and control group (3rd and 5th column) in post-intervention or period 1. 
Table 2. Pattern of missing data and characteristics of intervention and control group in period 0 (pre-intervention) (n=1247).

\begin{tabular}{|c|c|c|c|c|}
\hline $1^{\text {st }}$ column & $2^{\text {nd }}$ column & $3^{\text {rd }}$ column & $4^{\text {th }}$ column & $5^{\text {th }}$ column \\
\hline & \multicolumn{2}{|c|}{ Intervention group $(n=742)$} & \multicolumn{2}{|c|}{ Control group $(n=505)$} \\
\hline & $\begin{array}{c}\text { Missing data (m) } \\
\mathrm{n}=393\end{array}$ & No missing data $(\mathrm{nm}) \mathrm{n}=349$ & $\begin{array}{c}\text { Missing data (m) } \\
\mathrm{n}=242\end{array}$ & $\begin{array}{c}\text { No missing data (nm) } \\
\mathrm{n}=263\end{array}$ \\
\hline \multicolumn{5}{|l|}{ Socioeconomic } \\
\hline Age at the beginning of program & $16.97(1.11)$ & $16.75(1.00)^{* * * *}$ & $17.04(1.08)$ & $16.35(0.87)^{* * * *}$ \\
\hline Being female & $0.53(0.5)$ & $0.55(0.5)$ & $0.51(0.5)$ & $0.53(0.5)$ \\
\hline Being Spanish & $0.94(0.23)$ & $0.97(0.18)$ & $0.93(0.25)$ & $0.94(0.24)$ \\
\hline Being catholic & $0.61(0.49)$ & $0.64(0.48)$ & $0.6(0.49)$ & $0.61(0.49)$ \\
\hline No religion & $0.32(0.47)$ & $0.31(0.46)$ & $0.34(0.48)$ & $0.33(0.47)$ \\
\hline Type of family composition: nuclear & $0.72(0.45)$ & $0.77(0.42)$ & $0.74(0.44)$ & $0.75(0.44)$ \\
\hline Family functionality: APGAR & $1.64(0.59)$ & $1.72(0.54)^{* *}$ & $1.73(0.52)$ & $1.72(0.53)$ \\
\hline Mother's schooling years & $11.23(3.34)$ & $11.19(3.33)$ & 11.14(3.62) & $12.37(2.85)^{* * * *}$ \\
\hline Father's schooling years & $10.86(3.44)$ & $11.25(3.28)$ & $10.59(3.82)$ & $12.04(3.2)^{* * *}$ \\
\hline Current job situation of the mother & $0.62(0.49)$ & $0.65(0.48)$ & $0.62(0.49)$ & $0.77(0.42)^{* *}$ \\
\hline Current job situation of the father & $0.75(0.43)$ & $0.84(0.37)^{* *}$ & $0.76(0.43)$ & $0.69(0.46)^{* *}$ \\
\hline Good economic situation at home & $0.40(0.49)$ & $0.50(0.50)^{* * *}$ & $0.46(0.5)$ & $0.53(0.5)$ \\
\hline Economic difficulties at home & $0.37(0.48)$ & $0.36(0.48)$ & $0.3(0.46)$ & $0.28(0.45)$ \\
\hline Pocket money (weekly) (2017) & $11.31(9.51)$ & $9.82(8.52)^{* * *}$ & $11.84(10.22)$ & $10.61(0.16)$ \\
\hline Complete the questionnaire at end of the week & $0.68(0.47)$ & $0.72(0.45)$ & $0.8(0.4)$ & $0.58(0.5)^{* * *}$ \\
\hline \multicolumn{5}{|l|}{ Alcohol consumption and BD } \\
\hline Number of occasions of BD & $1.34(2.11)$ & $0.89(1.83)^{* * *}$ & $1.18(2.04)$ & $1.06(2.21)$ \\
\hline Alcohol use on last weekend & $0.27(0.45)$ & $0.19(0.4)^{* *}$ & $0.23(0.42)$ & $0.2(0.4)$ \\
\hline Frequency alcohol use in public outdoor places & $1.26(2.25)$ & $1.12(2.32)$ & $1.12(2.20)$ & $1.1(2.2)$ \\
\hline in parties or celebrations & $1.65(2.64)$ & $1.43(2.5)$ & $1.47(2.35)$ & $1.49(2.42)$ \\
\hline “...” at home or someone else's home & $1.04(2.1)$ & $0.87(2.04)$ & $1.12(2.34)$ & $1.09(2.24)$ \\
\hline Glasses of alcohol consumed in outdoor public places & $1.7(2.11)$ & $1.57(2.16)$ & $1.68(2.39)$ & $1.29(1.9)^{* *}$ \\
\hline in parties or celebrations & $2.53(2.7)$ & $2.45(2.66)$ & $2.66(2.63)$ & $2.39(2.6)$ \\
\hline
\end{tabular}




\begin{tabular}{|c|c|c|c|c|}
\hline “...” at home or someone else's home & $1.4(1.91)$ & $1.24(2.05)$ & $1.53(2.18)$ & $1.41(2.04)$ \\
\hline Mother consumes alcohol moderately/more frequently & $0.24(0.43)$ & $0.22(0.42)$ & $0.25(0.44)$ & $0.31(0.46)^{*}$ \\
\hline Father consumes alcohol moderately/more frequently & $0.4(0.5)$ & $0.44(0.5)$ & $0.44(0.5)$ & $0.44(0.5)$ \\
\hline Siblings consume alcohol moderately/more frequently & $0.24(0.42)$ & $0.21(0.41)$ & $0.25(0.43)$ & $0.23(0.42)$ \\
\hline Partner consumes alcohol moderately/more frequently & $0.2(0.4)$ & $0.16(0.37)$ & $0.16(0.37)$ & $0.15(0.35)$ \\
\hline Friends consume alcohol moderately/more frequently & $0.82(0.38)$ & $0.81(0.4)$ & $0.82(0.38)$ & $0.81(0.39)$ \\
\hline Best friend consumes alcohol moderately/more frequently & $0.61(0.49)$ & $0.56(0.5)$ & $0.55(0.5)$ & $0.54(0.5)$ \\
\hline Mother binge drinks more frequently & $0.06(0.23)$ & $0.04(0.2)$ & $0.08(0.28)$ & $0.07(0.25)$ \\
\hline Father binge drinks more frequently & $0.15(0.36)$ & $0.16(0.37)$ & $0.17(0.38)$ & $0.15(0.36)$ \\
\hline Siblings binge drink more frequently & $0.15(0.35)$ & $0.11(0.31)$ & $0.15(0.36)$ & $0.15(0.36)$ \\
\hline Partner binge drinks more frequently & $0.13(0.33)$ & $0.11(0.31)$ & $0.12(0.32)$ & $0.11(0.31)$ \\
\hline Friends binge drink more frequently & $0.7(0.46)$ & $0.67(0.47)$ & $0.69(0.46)$ & $0.59(0.49)^{* * *}$ \\
\hline Best friend binge drinks more frequently & $0.48(0.5)$ & $0.41(0.49)^{* *}$ & $0.44(0.5)$ & $0.34(0.48)^{* *}$ \\
\hline \multicolumn{5}{|l|}{ Other consumptions } \\
\hline Being a smoker & $0.21(0.41)$ & $0.24(0.43)$ & $0.25(0.44)$ & $0.22(0.41)$ \\
\hline Number of cigarettes a week & $5.95(16.34)$ & 2.93(11.15) & $5.24(17.49)$ & 2.8(11.96) \\
\hline Number of shishas or hookahs a week & $0.73(2.48)$ & $0.9(2.5)$ & $0.7(2.01)$ & $1.4(3.33)$ \\
\hline User of cannabis & $0.07(0.26)$ & $0.05(0.22)$ & $0.10(0.3)$ & $0.07(0.25)^{*}$ \\
\hline Prescribed tranquilisers, sedatives or sleeping pills & $0.02(0.15)$ & $0.01(0.12)$ & $0.04(0.2)$ & $0.02(0.15)$ \\
\hline Non-prescribed tranquilisers, sedatives or sleeping pills & $0.01(0.1)$ & $0.01(0.12)$ & $0.04(0.19)$ & $0.02(0.14)$ \\
\hline
\end{tabular}

Note: we show the average values and standard deviations in brackets. ${ }^{* * *},{ }^{* * *}$ and ${ }^{*}$ represent statistically significant differences at $1 \%, 5 \%$ and $10 \%$ between values of variables with missing data and no-missing data in intervention and control group ( $3^{\text {rd }}$ and $5^{\text {th }}$ column). 
Table 3. Comparison of marginal effects of intervention impact on the reduction of the number of occasions of BD and the EQ-5D-5L between periods.

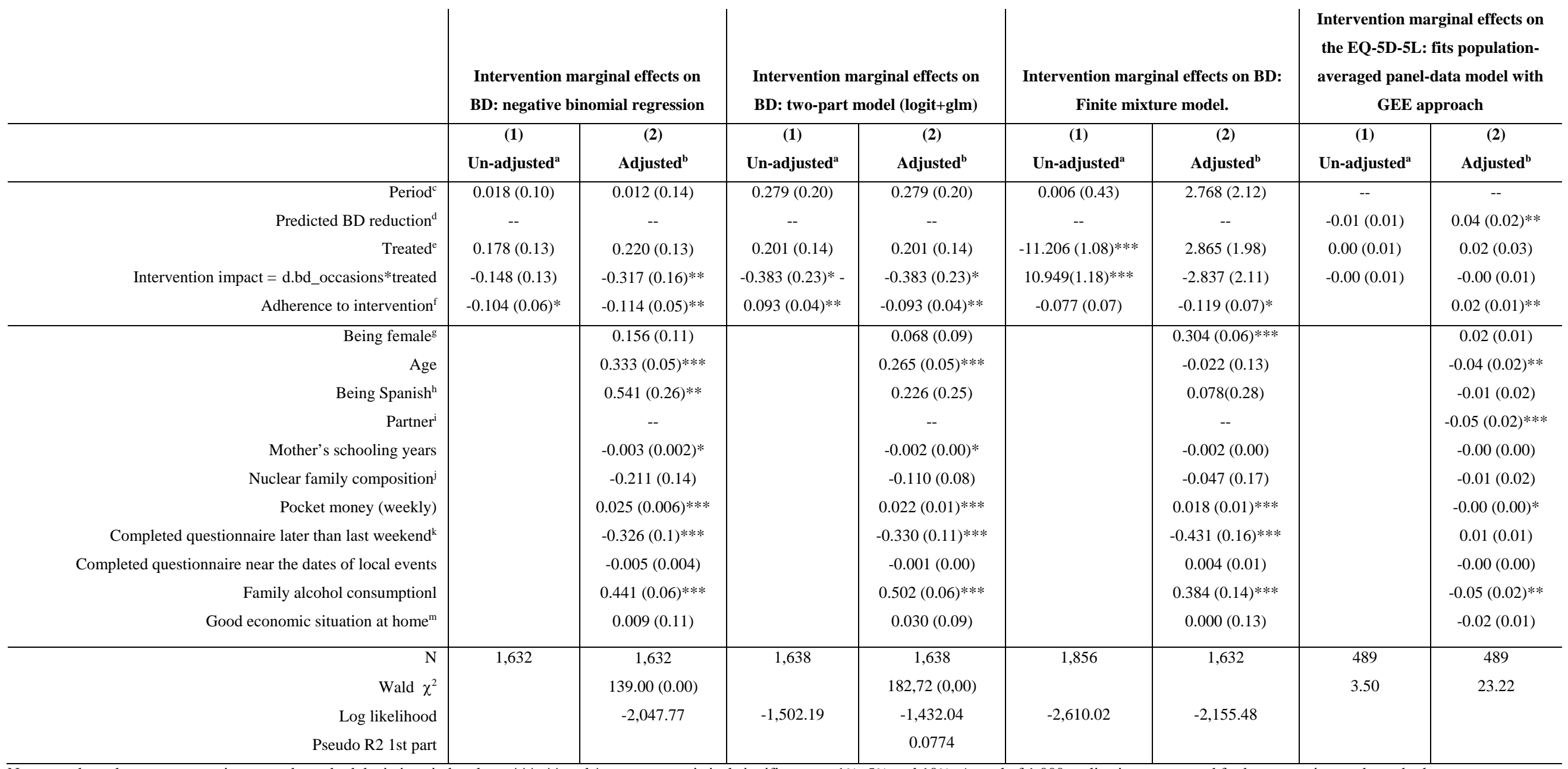

Note: we show the parameter estimates and standard deviations in brackets. ${ }^{* * *}$, ** and * represent statistical significance at $1 \%, 5 \%$ and $10 \%$. A total of 1,000 replications were used for bootstrapping, and standard errors were clustered at the branch level.

${ }^{a}$ Un-adjusted: only controlled by period (pre or post intervention), allocation (intervention or control group), adherence to intervention and intervention impact.

${ }^{\mathrm{b}}$ Adjusted: controlled by gender, age, nationality, having partner, mother's schooling years, type of family, weekly pocket money, family alcohol consumption, economic situation at home,... 
c1=period post intervention 1; $0=$ period pre intervention

d $1=$ intervention group; $0=$ control group

e $1=$ being female; $0=$ male

$1=$ being Spanish; $0=$ others

g $1=$ having partner; $0=$ no having partner

h 1 =nuclear family (father, mother and/or brother(s) and sister(s)); $0=0$ others

${ }^{\mathrm{i}}$ Completed questionnaire later than last weekend: $1=$ Filled questionnaire on Wednesday, Thursday or Friday; $0=$ Filled questionnaire on Monday or Tuesday

j Family alcohol consumption: $0=$ Mother, father and siblings did not binge drinking from moderate or more frequently; $1=$ Mother or father or siblings did binge drinking from moderate or more frequently; $2=$ Two

members of the family (mother, father or siblings) did binge drinking from moderate or more frequently ; $3=$ Mother, father and siblings did binge drinking from moderate or more frequently.

k $1=$ Good economic situation at home; $0=$ Other. 